\title{
Step Reflex
}

National Cancer Institute

\section{Source}

National Cancer Institute. Step Reflex. NCI Thesaurus. Code C81322.

An involuntary, primal response in the neonate to take brisk steps when the feet are placed on a surface whilst in a supported standing position. 